\title{
Atazanavir (ATV) plasma concentrations at different times after drug uptake: associations with virologic response and hyperbilirubinemia
}

\author{
M Fabbiani*1, S Di Giambenedetto ${ }^{1}$, E Ragazzoni ${ }^{2}$, M Colafigli ${ }^{1}$, M Prosperi ${ }^{1}$, \\ R Cauda1 ${ }^{1}$ P Navarra ${ }^{2}$ and A De Luca ${ }^{1}$
}

\author{
Address: ${ }^{1}$ Istituto di Clinica delle Malattie Infettive, Università Cattolica del Sacro Cuore, Roma, Italy and ${ }^{2}$ Istituto di Farmacologia, Università \\ Cattolica del Sacro Cuore, Roma, Italy \\ * Corresponding author
}

\author{
from Ninth International Congress on Drug Therapy in HIV Infection \\ Glasgow, UK. 9-13 November 2008 \\ Published: 10 November 2008 \\ Journal of the International AIDS Society 2008, I I (Suppl I):P243 doi:I0.I I86/I758-2652-I I-SI-P243
}

This abstract is available from: http://www.jiasociety.org/content/II/SI/P243

(c) 2008 Fabbiani et al; licensee BioMed Central Ltd.

\section{Purpose of the study}

To explore the clinical significance of morning ATV plasma concentrations in HIV+ patients taking drugs at different day times.

\section{Methods}

HIV-infected patients on an ATV-containing cART regimen since $>2$ weeks, with an available ATV concentration obtained by a validated HPLC-UV (group i) $12 \pm 2$ hours (C12 h) and (group ii) $24 \pm 2$ hours (C24 h) after drug intake and 24 weeks subsequent virological follow-up, were retrospectively selected. Patients with genotypic resistance to ATV were excluded. Virological failure was defined as HIV-RNA $>50$ copies/ml after 24 weeks.

\section{Summary of results}

A total of 171 plasma samples from 112 patients (56\% males, median age 46 years IQR 40-51) were analyzed. Median time from ATV initiation was 8.9 months (IQR 1.9-17.2). At ATV dosing, $79.5 \%$ of patients had a viral load $<50$ copies $/ \mathrm{ml}$. Overall, 27 (24.1\%) showed virological failure at 24 weeks. No significant differences in terms of virological failures were seen between ritonavirboosted and unboosted regimens. Median ATV plasma concentration was higher in patients using boosted regimens: $1.5 \mathrm{mg} / \mathrm{L}$ (IQR $0.58-2.30$ ) vs. $0.27 \mathrm{mg} / \mathrm{L}$ (IQR $0.05-1.15), \mathrm{p}<0.01$.
$\mathrm{C} 12 \mathrm{~h}$ ATV concentrations were measured in 115 instances while C24 h in 56 samples. Median ATV plasma concentration was significantly higher in group (i) compared to group (ii): $1.5 \mathrm{mg} / \mathrm{L}$ (IQR $0.7-2.3$ ) vs. $0.26 \mathrm{mg} / \mathrm{L}$ (IQR 0.07-0.67), $\mathrm{p}<0.01$. Plasma concentration showed a high interindividual variability in both groups (co-efficient of variation $83.3 \%$ and $146.8 \%$, respectively).

In group (i), ROC curve test provided an ATV concentration cut-off of $0.23 \mathrm{mg} / \mathrm{L}$ to predict virological response at 24 weeks: instances $(\mathrm{n}=17)$ with a $\mathrm{C} 12 \mathrm{~h} \leq 0.23 \mathrm{mg} / \mathrm{L}$ showed virological failure in $41.2 \%$, whereas instances (n $=98)$ with a C12 h $>0.23 \mathrm{mg} / \mathrm{L}$ failed in $16.3 \%$ of cases (p $=0.042)$. A total of $22.5 \%$ (20/89) of patients developed grade III/IV hyperbilirubinaemia. ATV $\mathrm{C} 12 \mathrm{~h}$ correlated with concomitant unconjugated bilirubin $(\mathrm{r}=0.223, \mathrm{p}=$ $0.037)$. A concentration cut-off predictive of $>$ grade III total bilirubin toxicity could not be identified. No correlations were identified between $\mathrm{C} 24 \mathrm{~h}$ and virologic response or bilirubinemia.

\section{Conclusion}

Identification of an ATV C12 h efficacy threshold can be useful for the clinical application of morning TDM in patients receiving ATV at night. 